\title{
Harnessing E-Collaboration for Rural Tourism Recovery after COVID-19: Dual Analysis using SWOT and Porter's Diamond Model
}

\author{
Mardiana Purwaningsih ${ }^{1,2}$, Betty Purwandari ${ }^{1 *}$, Fathia Prinastiti Sunarso ${ }^{1}$, \\ Farisya Setiadi ${ }^{1,3}$ \\ ${ }^{1}$ Faculty of Computer Science, Universitas Indonesia, Depok, Indonesia \\ ${ }^{2}$ Faculty of Information Technology, Perbanas Institute, Jakarta, Indonesia \\ ${ }^{3}$ National ICT Council, Jakarta, Indonesia
}

\begin{abstract}
IT for rural tourism was in place before the COVID-19 pandemic emerged; however, the initiatives were intermittent and isolated. The effects of the pandemic encourage e-collaboration to accelerate the recovery of tourism. This study explores the opportunities, strategies and barriers to ecollaboration in tourism business activities. Systematic literature studies were carried out by the PRISMA approach and analyzed with the fuzzy Delphi method (FDM). Meta-analysis results are mapped in a matrix combination of SWOT and Porter's Diamond Model. This matrix was discussed with experts selected based on their experience in IT-based collaborative activities through FDG. This study's driving factors are management commitment, culture, trust, citizens, and local community involvement. Inhibiting factors are a lack of IT, the risk of conflict, and particular parties' domination. Several strategies to increase e-collaboration opportunities are empowering local entrepreneurship, encouraging continuous innovation, and sharing knowledge. Conflict management and increasing trust between members need to be considered to overcome barriers to ecollaboration. This study provides a novel overview of the main issues discussed in previous tourism research regarding the importance of IT to accelerate economic recovery in the face of disruption, such as a pandemic. The study examines the case of Indonesia and hopes to become a reference for optimizing IT for the recovery of rural tourism in developing countries with similar characteristics.
\end{abstract}

\author{
Keywords: \\ e-collaboration; Rural Tourism; \\ COVID-19; SWOT; \\ Porter's Diamond Model; \\ PRISMA; \\ Fuzzy Delphi Method. \\ Article History:

$\begin{array}{llll}\text { Received: } & 23 & \text { April } & 2021 \\ \text { Revised: } & 15 & \text { July } & 2021 \\ \text { Accepted: } & 24 & \text { July } & 2021 \\ \text { Published: } & 01 & \text { August } & 2021\end{array}$

\section{1- Introduction}

The tourism industry was significantly affected by the COVID-19 pandemic. This impact was caused by many countries' policies that implemented physical distancing to prevent the virus's spread. International and local travel restrictions resulted in a drastic reduction in tourist numbers [1]. This decline immediately affected tourism and industries directly related to tourism, such as aviation, public transportation, accommodation, and restaurants [2, 3]. Several studies related to post-COVID-19 tourism discuss changes in tourist behavior and sustainable tourism models $[2,4]$. To date, no study has specifically discussed strategies for restoring the tourism industry after the current pandemic subsides. Some countries began to loosen physical distancing policies in the summer of 2021, and systematic steps may be needed to improve the tourism industry. This situation requires policy recommendations for both the medium and long term, including strengthening the supply side, strengthening attractions, strengthening access, and cultivating the demand side [5].

\section{*CONTACT: bettyp@cs.ui.ac.id}

DOI: http://dx.doi.org/10.28991/esj-2021-01297

(C) 2021 by the authors. Licensee ESJ, Italy. This is an open access article under the terms and conditions of the Creative Commons Attribution (CC-BY) license (https://creativecommons.org/licenses/by/4.0/). 
To increase access, the recommendations strongly emphasize the optimization of IT to harmonize information and tourism agendas throughout Indonesia [5]. This study focuses on the rural tourism industry because rural tourism has multiple effects that will raise other economic potentials that also collapsed with the imposition of physical restrictions. Rural tourism development will eventually become a development mechanism for socio-economic contributions [6, 7], open entrepreneurial opportunities, create jobs, and support retail growth [8]. Rural areas also offer potential by providing extraordinary natural resources as valuable places of rest after a long quarantine period [9].

Several attempts have been made to use IT to develop the tourism industry, such as travel websites to review tourist attractions, e-commerce websites to provide marketing and transactions for tourists, and mobile applications for scanning sites [10-12]. However, these initiatives are often sporadic and disconnected, thus becoming an obstacle for rural tourism to reach its full potential. The need to collaborate and optimize IT to accelerate post-pandemic tourism is the basis for developing an electronic collaboration with actors outside the traditional tourism industry with better IT usage capabilities. Small and medium enterprises (SMEs) are the tourism-related businesses most vulnerable to the effects of the crisis [13]. SMEs will find it very difficult to restore their businesses independently after the pandemic. Therefore, a post-pandemic collaboration could accelerate the recovery of economic conditions in the tourism industry [14]. Collaboration is defined as a network consisting of several actors, including individuals, groups of individuals, companies, parts of companies, or groups of companies working together to achieve common goals [6, 15, 16]. The term "e-collaboration" is a collaboration carried out without face-to-face interaction using technology [17, 18].

Although e-collaboration in rural areas has a great opportunity to accelerate economic recovery and sustainably increase the economy, studying and understanding the issues before implementation is important. This study explores the e-collaboration opportunities and barriers in tourism business activities by understanding the extent to which these small businesses face collaboration challenges at various stages of their business life cycle. This study also examines overcoming this collaborative challenge with multiple strategies to increase opportunities and anticipate these obstacles. E-collaboration can expose activities regarding sharing knowledge, resources, marketing, and capabilities that are not owned by the business itself [14]. In general, the current state of e-collaboration is seen as something new or unfamiliar, so in many cases, there is still a lack of understanding and low adoption of online collaboration tools in tourism networks, especially in rural areas. Successfully carrying out a digital transformation can result in business continuity for the SMEs both now and in the future [19]. Given that e-collaboration creates new business opportunities for rural tourism, research that aims to prepare e-collaboration utilization strategies to accelerate rural tourism recovery is very relevant and urgent.

The e-collaboration factors and strategies for rural tourism are analyzed using a combination of the SWOT (Strengths, Weaknesses, Opportunities, Threats) model and Porter's Diamond Model National Competitive Advantage approach. SWOT helps formulate strategies for creating and capturing value by maintaining a competitive advantage and exploring new market opportunities [20]. SWOT is a relatively simple but powerful analysis tool that can help organizations analyze a business's internal resources and match them to the external environment [21, 22]. However, classifying one variable into the four SWOT quadrants can be a challenge. A factor can fit in more than one quadrant. The criteria for assigning a variable to one of the four SWOT quadrants are even more challenging to establish if the analysis objective is a country rather than an organization [23]. Porter's Diamond Model of National Competitive Advantage theory states that a country gains a competitive advantage if companies in that country are competitive. The competitiveness of a country is determined by its industries' ability to innovate and improve their capabilities. This study uses a combination of SWOT analysis with Porter's Diamond Model of National Competitive Advantage to understand this competitiveness precisely.

Information was systematically collected using a literature study based on a specific protocol. The protocol used in this study is PRISMA which allows the literature review process to avoid bias and subjective understanding of the researchers [24]. The Fuzzy Delphi method (FDM) is used to achieve consensus from experts regarding future projections and trends using a systematic process of gathering information [25]. Combining these two methods is expected to increase the validity of e-collaboration factors and strategies for rural tourism derived from the literature.

This paper's original contribution is an overview of the main issues discussed in previous tourism research regarding the importance of IT to accelerate economic recovery in the face of disruption, such as a pandemic. This research provides new insights into tourism's technological developments by applying the theory and methodology developed in the information systems discipline. It proposes a research agenda by identifying research gaps and opportunities for future research collaborations between information technology and tourism studies.

\section{2- Research Methodology}

The purpose of this study is to explore e-collaboration opportunities and obstacles in developing rural tourism and various strategies based on the identified opportunities and barriers. Previous researchers have carried out similar studies that were published in many academic publications. A systematic method is needed to collect research results 
relevant to the research question, followed by a selection and meta-analysis process. Identified issues are then compiled in a questionnaire and distributed to experts. The processing of the questionnaire results used the fuzzy Delphi method to reach a consensus. Figure 1 shows the method adopted from previous studies, with some adjustments to the research conducted [26].

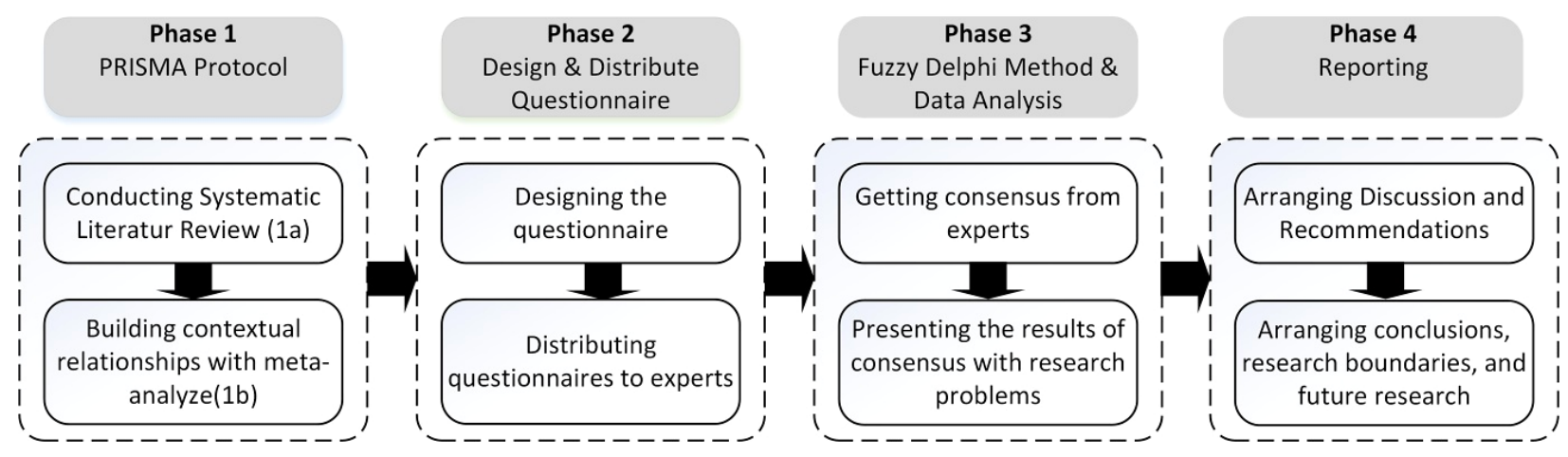

Figure 1. Overall Research Stages.

\section{2-1-Phase 1 - PRISMA Protocol (Preferred Reporting Items for Systematic Reviews and Meta-analyses)}

PRISMA is a literature review reporting guideline protocol developed to optimize systematic literature [24, 27-30]. This study was conducted from April-October 2020 to identify, evaluate, and interpret research results relevant to ecollaboration to develop rural tourism. The literature was collected from well-known journals, international conferences, and several studies published in books and working papers. Data sources use five electronic databases: Science Direct, ACM Digital Library, IEEE, SpringerLink, and Google Scholar. The concept terminology used in finding articles in this electronic database is e-collaboration. The selected keywords are accompanied by their synonyms, considering that studies use different terminologies when discussing the opportunity and obstacle factors, such as components, elements, or critical success factors. Synonyms for the word "electronic" are "digital" and "virtual," and synonyms for "collaboration" are "relationship," "networking," and "partnership." The Boolean operator "OR" is used to enter alternative search terms. The Boolean operator "AND" links two search strings containing two or more concepts. The asterisk symbol "*”" is used after a word to enter variations of the search term.

Table 1. Research Question.

\begin{tabular}{ll}
\hline \multicolumn{1}{c}{ Research Question } & \multicolumn{1}{c}{ Description of Objective } \\
\hline $\begin{array}{l}\text { Q1: What are the factors influencing the success of e- } \\
\text { collaboration in rural tourism development? }\end{array}$ & $\begin{array}{l}\text { To identify factors supporting and inhibiting e-collaboration in } \\
\text { tourism development in rural areas. }\end{array}$ \\
$\begin{array}{ll}\text { Q2: What are the e-collaboration strategies } \\
\text { recommended in rural tourism development? }\end{array}$ & $\begin{array}{l}\text { To identify various recommendations for using e-collaboration } \\
\text { for tourism development in rural areas? }\end{array}$ \\
\hline
\end{tabular}

Thus, a systematic review is also a synthesis of research with related topics accompanied by several balanced and comprehensive facts in preparing e-collaboration utilization strategies. The next stage in the literature study is to carry out a meta-method process with NVivo 12 Software. Presentation of the meta-method results uses a combination matrix of the SWOT model and Porter's Diamond Model National Competitive Advantage. SWOT analysis is a strategic planning analysis method used to monitor and evaluate a company's external and internal environment for specific business objectives [20]. Strengths and Weaknesses come from within the company and can be controlled and changed. Opportunities and Threats are externalities that affect the business or situations outside the company in a larger market. Companies can take advantage of opportunities and protect against threats but cannot change them.

Porter's Diamond Model consists of four determinants: factor conditions, demand conditions, related and supporting industries, and firm strategy, structure, and rivalry. These determinants make it possible to analyze the performance of an organization at the national level [31-33]. The factor conditions determinant refers to inputs used as production factors, such as labor, natural resources, capital, and infrastructure. The demand conditions determinant refers to the availability of a domestic market ready to play an essential role in generating competitiveness. A market like this is characterized by selling products with good quality, driven by the demand for quality goods or services, and a good relationship between the company and customers. The related and supporting industries determinant refers to the availability of a series and the strong relationship between the supporting industry and the company; this relationship and support are positive, leading to increased competitiveness. Firm strategy, structure, and rivalry determinants refer to most companies' systems and networks and competition intensity in specific industries [31-33]. 


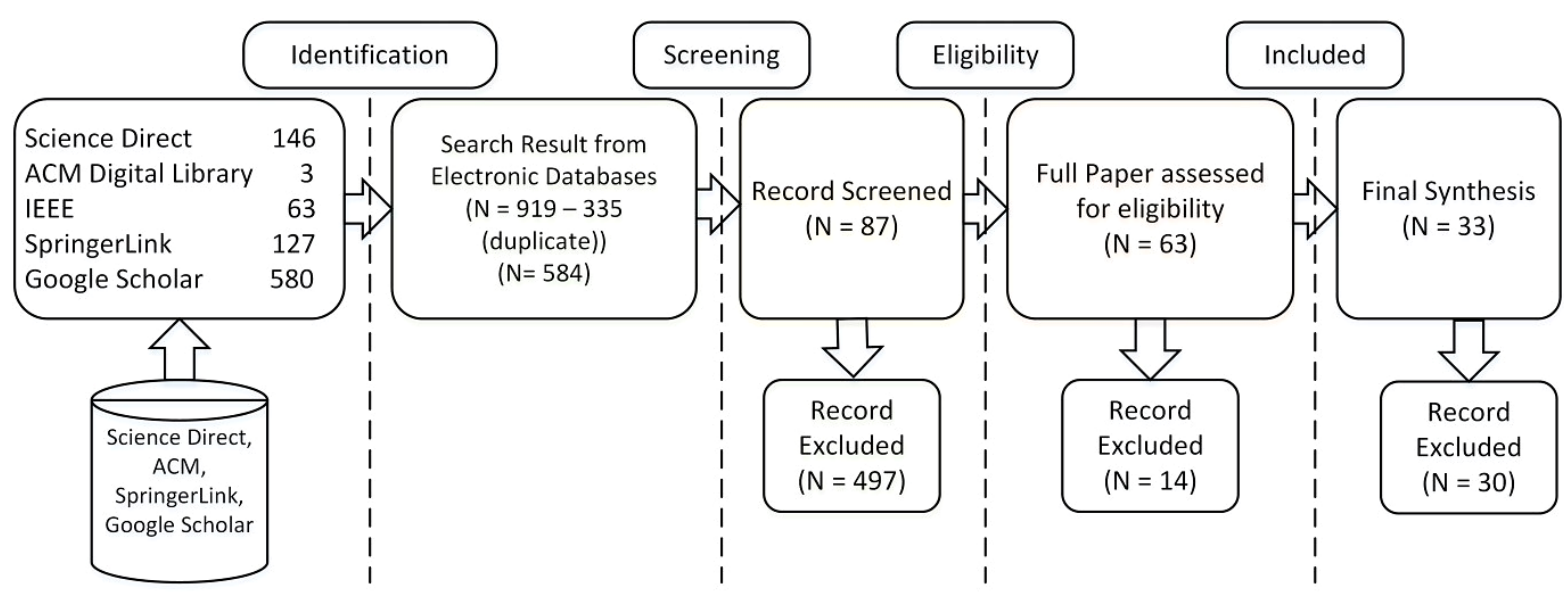

Figure 2. The research workflow is adapted from PRISMA (1a).

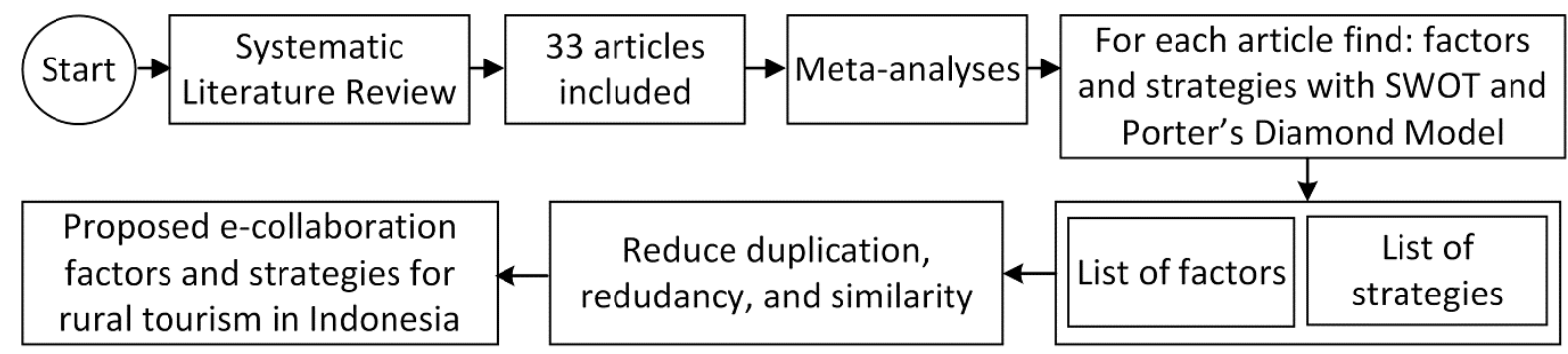

Figure 3. Meta-analyses steps (1b).

\section{2-2-Phase 2 - Experts Validation}

The next step is to perform expert validation to assess the meta-analyze results modeled using the combined approach of SWOT and Porter's Diamond Model. At this stage, a group of experts was selected to provide input and estimate the factors and strategies prioritized in an e-collaboration for tourism development in rural areas. This expert panel is a group of competent people in the scope of a particular field of study [25], selected based on their position and experience in information technology-based collaborative activities. They have significant practical knowledge in their field. The expert panel also represents community groups to provide a comprehensive picture of e-collaboration in rural tourism.

The selected experts are eight people from four backgrounds (academics, practitioners, local government officials, and tourism businesses) representing some of the actors involved in an e-collaboration. The academics have research experience in the ICT field aimed at developing rural areas. The practitioners have at least five years of experience studying ICT projects used in rural area development. The selected local government officials are stakeholders in the area who have started to use ICT to manage the economic potential, including tourism. The tourism community also continues to innovate during the pandemic by pioneering virtual tours and involving tourism ecosystem stakeholders. The questionnaire for the expert panel uses a Likert scale and consists of two parts. The first part analyzes opportunities and barriers to e-collaboration in rural tourism development divided into a combined SWOT and Porter's Diamond Model matrix. The second part addresses the e-collaboration strategy in developing rural tourism, which is divided into four parts. The questionnaire was distributed to experts using e-mail. An online interview was planned to gather more information about some answers.

\section{2-3-Phase 3 - Consensus determination using the Fuzzy Delphi Method}

FDM combines traditional Delphi techniques and fuzzy set theory, which considers human linguistic preferences in making decisions [34, 35]. FDM addresses the imperfections of traditional Delphi techniques, which can lead to low convergence in decision making, the risk of losing important information, and long execution times [34]. However, the data used in decision-making by experts in FDM must go through a systematic process with a strict protocol to produce a quality consensus [25]. FDM is widely applied in various domains, including humanities, management, business, physics, and engineering [34], and has been tested in previous studies [25, 26]. The consensus obtained from the FDM process is used as a recommendation by decision-makers. 


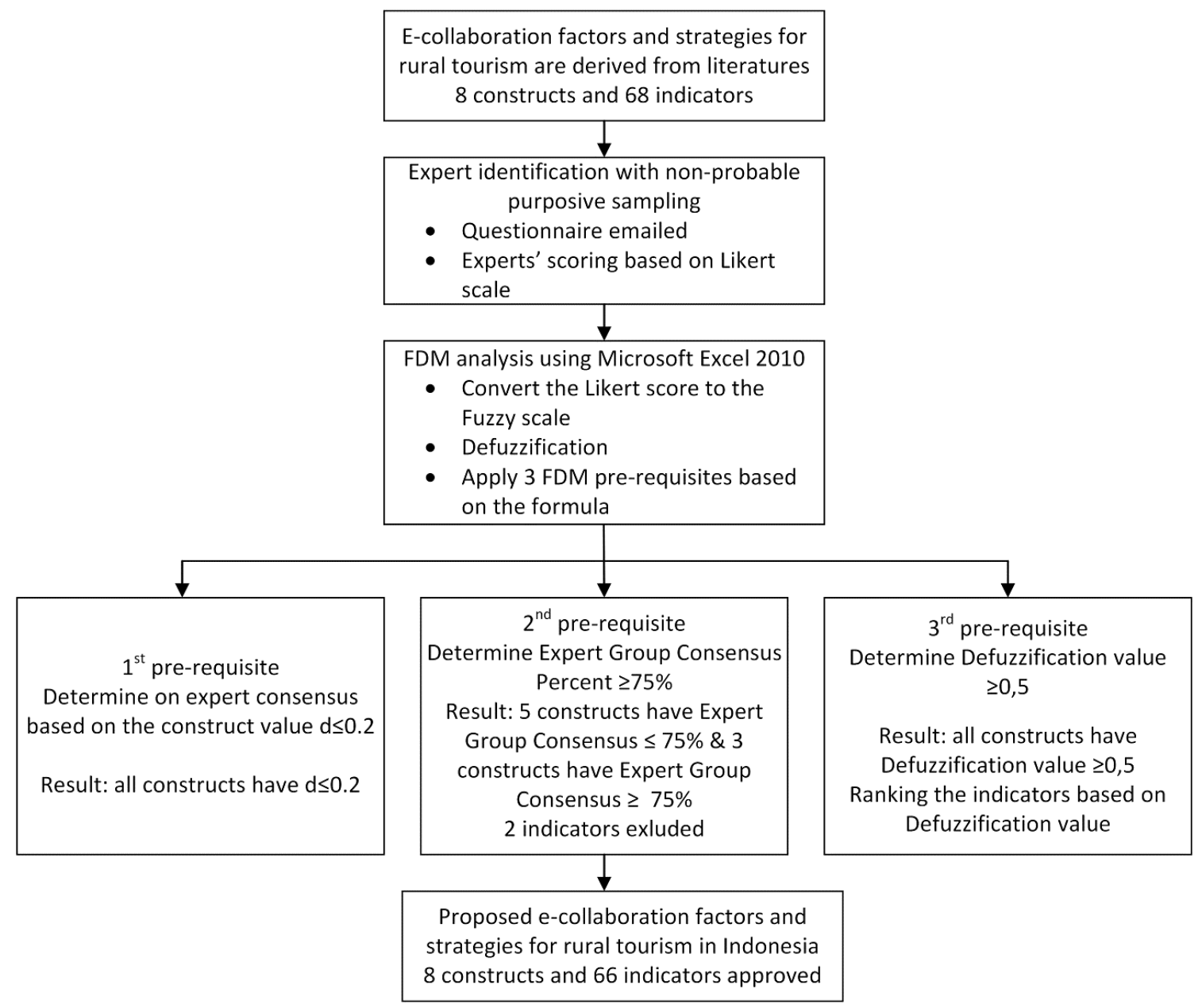

Figure 4. Summary of Fuzzy Delphi Method Phase.

In FDM, the researcher identifies a group of experts and then defines that a consensus requires the agreement of at least $75 \%$ of the experts. If the agreement is less than $75 \%$, researchers repeat the procedure to ensure a $75 \%$ consensus among the experts. If the item has not reached $75 \%$ agreement, the experts will provide their individual opinion regarding this indicator.

Experts' questionnaires were converted according to the fuzzy scale in Table 2. All experts were considered to have reached a consensus agreement when the threshold value $d \leq 0.2$. When an indicator has a threshold value of $d>0.2$, the researchers repeat the procedure and confirm the results with the experts. FDM's next step is to perform a fuzzy evaluation, as one of the most reliable methods of determining ratings, using the formula $\mathrm{A}_{\max }=1 / 3 *(\mathrm{a} 1+\mathrm{am}+\mathrm{a} 2)$.

Table 2. Variable for the importance weight of criteria.

\begin{tabular}{ccccc}
\hline Likert Scale Scoring & Linguistic variable & \multicolumn{3}{c}{ Fuzzy Scale Scoring } \\
\hline 5 & Strongly agree & 0.6 & 0.8 & 1.0 \\
4 & Agree & 0.4 & 0.6 & 0.8 \\
3 & Moderately /Not Sure & 0.2 & 0.4 & 0.6 \\
2 & Not Agree & 0.0 & 0.2 & 0.4 \\
1 & Strongly Not Agree & 0.0 & 0.0 & 0.2 \\
\hline
\end{tabular}

\section{2-4-Phase 4-Preparing the Report}

The FDM analysis results are used to compile the Discussions and Recommendations sections of this article, and also for conclusions, formulating research boundaries, and as the input for further research.

\section{3- Result}

According to the research question, the paper-selection results used in the synthesis process were 33 papers for the Meta-analyze stage (Table 3). 
Table 3. Final Results of Paper Selection for Meta-Analyses Process.

\begin{tabular}{|c|c|c|c|c|c|c|c|c|}
\hline No. & Code & Reference & No. & Code & Reference & No. & Code & Reference \\
\hline 1 & $\mathrm{C} 1$ & Bremser et al. (2019) [36] & 12 & $\mathrm{~J} 7$ & Bichler and Lösch (2019) [37] & 23 & $\mathrm{C} 5$ & Zeiller and Schauer (2011) [38] \\
\hline 2 & $\mathrm{~J} 1$ & Abou-Shouk et al. (2013) [39] & 13 & J8 & Pons-Morera et al. (2018) [40] & 24 & B3 & Lock and Redmond (2010) [41] \\
\hline 3 & $\mathrm{~J} 2$ & Chiodo et al. (2019) [42] & 14 & $\mathrm{C} 3$ & Bremser et al. (2019) [43] & 25 & $\mathrm{~J} 15$ & Hamari et al. (2016) [44] \\
\hline 4 & $\mathrm{C} 2$ & Fachrunnisa et al. (2013) [45] & 15 & $\mathrm{C} 4$ & Jeon and Dagravel (2017) [46] & 26 & $\mathrm{~J} 16$ & Perkins and Khoo (2019) [7] \\
\hline 5 & W1 & Chapman and Slaymaker (2002) [47] & 16 & J9 & Brunetto and Farr (2007) [48] & 27 & C6 & Johson et al. (2020) [49] \\
\hline 6 & $\mathrm{~J} 3$ & Kennedy and William (2012) [50] & 17 & $\mathrm{~J} 10$ & Ngo et al. (2019) [51] & 28 & B4 & Kumar et al. (2017) [52] \\
\hline 7 & $\mathrm{~J} 4$ & Docherty et al. (2004) [53] & 18 & $\mathrm{~B} 2$ & Sigala and Robinson (2019) [54] & 29 & $\mathrm{~J} 17$ & Duglio et al. (2019) [55] \\
\hline 8 & W2 & Tremblay and Wegner (2009) [56] & 19 & $\mathrm{~J} 11$ & Burgess et al. (2012) [15] & 30 & $\mathrm{C} 7$ & Kolaczek et al. (2008) [9] \\
\hline 9 & J5 & Wondirad et al. (2020) [57] & 20 & $\mathrm{~J} 12$ & Cai (2005) [58] & 31 & $\mathrm{~J} 18$ & Nezakati et al. (2015) [59] \\
\hline 10 & J6 & Ma (2009) [60] & 21 & $\mathrm{~J} 13$ & Hardy et al. (2003) [61] & 32 & J19 & Thomson and Perry (2006) [62] \\
\hline 11 & B1 & Deuchar and Milne (2016) [16] & 22 & $\mathrm{~J} 14$ & Ramayah et al. (2011) [63] & 33 & $\mathrm{~J} 20$ & Keyim (2015) [6] \\
\hline
\end{tabular}

Code: C: Conference; J: Journal; W: Working Paper; B: Book Section

\section{3-1-e-Collaboration Success Factors for Rural Tourism}

The literature search results for the first research question, the driving and inhibiting factors of any e-collaboration in rural tourism development, are presented in Table 4. Each indicator is coded with three capital letters representing the SWOT dimension, mapped to each determinant in the Porter-Diamond model. This section contains four constructs, and each construct is preceded by the SWOT dimension, followed by the determinant of the PorterDiamond model, and given a serial number.

Table 4. Dimensions of SWOT vs. Porter's Diamond Determinants.

\begin{tabular}{|c|c|c|c|c|}
\hline \multirow{2}{*}{$\begin{array}{l}\text { Porter's Diamond } \\
\text { Determinants }\end{array}$} & \multicolumn{4}{|c|}{ Dimensions of SWOT } \\
\hline & Strengths & Weaknesses & Opportunities & Threats \\
\hline Factor Condition & $\begin{array}{l}\text { - Community empowerment and } \\
\text { local start-ups (C1) } \\
\text { - Taking advantage of an open and } \\
\text { modern technology platform to } \\
\text { improve the citizen's economy } \\
\text { (C1) } \\
\text { - Supporting } \\
\text { transactions (J1) }\end{array}$ & $\begin{array}{l}\text { - Lack of IT skills (J2, C2, W1) } \\
\text { - Resource constraints (including } \\
\text { funding) (C1, J1, J3-J5, W1- } \\
\text { W2) } \\
\text { - Cultural differences that hinder } \\
\text { the acceptance of new } \\
\text { technology (J4, J6) }\end{array}$ & $\begin{array}{l}\text { - Providing opportunities for } \\
\text { businesses to produce digital } \\
\text { content for their websites } \\
\text { (text, images, videos) (B1) } \\
\text { - e-collaboration supports } \\
\text { efforts to prepare product } \\
\text { diversity }\end{array}$ & - Information overload (J7) \\
\hline Demands Condition & $\begin{array}{l}\text { - e-collaboration will strengthen } \\
\text { market position (W2, J8) } \\
\text { - e-collaboration supports online } \\
\text { marketing based on WoM (Word } \\
\text { of Mouth) (W2) }\end{array}$ & $\begin{array}{l}\text { - Too much focus on technology } \\
\text { could ignore its conformity } \\
\text { with business needs (C3) }\end{array}$ & $\begin{array}{l}\text { - e-collaboration explores new } \\
\text { market potential (C4, J9) } \\
\text { - e-collaboration develops } \\
\text { collaborative marketing for } \\
\text { long-term business success } \\
\text { (J10) } \\
\text { - E-collaboration helps to } \\
\text { anticipate high demand for } \\
\text { seasonal travel (alternating } \\
\text { products and services in turn) } \\
\text { (B1) }\end{array}$ & \\
\hline $\begin{array}{l}\text { Related and } \\
\text { Supporting Industries }\end{array}$ & $\begin{array}{l}\text { - } \text { e-collaboration accommodates } \\
\text { resource sharing (B2) } \\
\text { - } \text { e-collaboration as a medium for } \\
\text { sharing knowledge } \quad \text { \& } \\
\text { collaborating in creating new } \\
\text { products (W2, B1, J7) } \\
\text { - e-collaboration facilitates the } \\
\text { involvement of fellow businesses } \\
\text { and residents (B1) } \\
\text { - e-collaboration becomes a } \\
\text { medium for sharing common } \\
\text { problems and finding solutions } \\
\text { (W2, B1, J9) }\end{array}$ & $\begin{array}{l}\text { - Low culture (tradition) of } \\
\text { collaboration and knowledge } \\
\text { sharing in society(C1, J5, J10- } \\
\text { J11) } \\
\text { - Lack of trust and mutual } \\
\text { understanding } \\
\text { stakeholders (J3, W2, J5-J7, } \\
\text { B1) } \\
\text { - An unequal commitment of } \\
\text { resources between members } \\
\text { (W2, J6) }\end{array}$ & $\begin{array}{l}\text { - In e-collaboration, public and } \\
\text { private companies can act as } \\
\text { innovators (C1) } \\
\text { - By joining e-collaboration, } \\
\text { the business will get support } \\
\text { from fellow businesses and } \\
\text { more advanced private parties } \\
\text { (W2) }\end{array}$ & $\begin{array}{l}\text { - A focus solely on } \\
\text { technology will ignore } \\
\text { citizen participation and } \\
\text { exacerbate the digital } \\
\text { divide }(\mathrm{C} 1) \\
\text { - There is dependence on } \\
\text { vendors/partners (C1, W2) } \\
\text { - Inevitable conflicts arise } \\
\text { during collaboration (J12) } \\
\text { - The domination of certain } \\
\text { parties in a partnership } \\
\text { (J13) }\end{array}$ \\
\hline $\begin{array}{l}\text { Firm Strategy, } \\
\text { Structure, and } \\
\text { Rivalry }\end{array}$ & $\begin{array}{l}\text { - e-collaboration makes the } \\
\text { administration process more } \\
\text { accessible, efficient, effective, and } \\
\text { transparent }(\mathrm{C} 1)\end{array}$ & $\begin{array}{l}\text { - There is no standard system } \\
\text { data model or IT governance } \\
\text { for e-collaboration }(\mathrm{C} 1, \mathrm{~J} 5) \\
\text { - The benefits of e-collaboration } \\
\text { often can only be felt in the } \\
\text { medium/long term (J4) } \\
\text { - e-collaboration models are } \\
\text { often only sector-specific or } \\
\text { target-driven projects (W1) }\end{array}$ & $\begin{array}{l}\text { - e-collaboration opens up new } \\
\text { business opportunities (C4, } \\
\text { J9) } \\
\text { - e-collaboration supports } \\
\text { changing market opportunities, } \\
\text { competition, and learning for } \\
\text { businesses (C2, W2) } \\
\text { - Promoting long-term business } \\
\text { success (C2, W2) }\end{array}$ & $\begin{array}{l}\text { - e-collaboration can exclude } \\
\text { or alienate communities } \\
\text { and institutions that } \\
\text { previously had a more } \\
\text { significant role in local } \\
\text { information and knowledge } \\
\text { systems (W1) }\end{array}$ \\
\hline
\end{tabular}




\section{3-2-e-Collaboration Strategies for Rural Tourism}

In the second research question, the e-collaboration strategy for rural tourism development is prepared using the SWOT approach to maximize the power of e-collaboration and minimize the obstacles.

\section{3-2-1- The SO Strategy (The Strength-Opportunity Strategy)}

The following statements should be made so that the power of e-collaboration can maximize its opportunities.

Table 5. The SO Strategy (The Strength-Opportunity Strategy).

\begin{tabular}{|c|c|c|}
\hline Code & Indicator & Reference Code \\
\hline SO01 & The existence of support and commitment from management. & $\mathrm{J} 3, \mathrm{~B} 1, \mathrm{~J} 14, \mathrm{C} 5$ \\
\hline SO02 & Improving coordination and communication, as well as focusing on synergies and services that provide added value. & $\mathrm{C} 1, \mathrm{~J} 3, \mathrm{~B} 3$ \\
\hline SO03 & Identifying the characteristics of networks and clusters in the area to enhance collaboration. & B1 \\
\hline SO04 & Strengthening core tourism competencies to improve the tourism experience in the region. & B1 \\
\hline SO05 & Empowering local start-ups (improving local entrepreneurship). & $\mathrm{C} 1$ \\
\hline SO06 & Encouraging continuous innovation in the tourism ecosystem. & W1 \\
\hline SO07 & Conducting business skills training, product commercialization, and effective business coaching for members. & $\mathrm{C} 2, \mathrm{~J} 3$ \\
\hline SO08 & Supporting the dissemination of information on local wisdom and the potential of an area in a sustainable manner. & W1 \\
\hline SO09 & Defining products and services clearly before joining in an electronic collaboration. & $\mathrm{J} 15$ \\
\hline
\end{tabular}

\section{3-2-2- The WO Strategy (The Weakness-Opportunity Strategy)}

The following statements should be made to overcome the weaknesses of e-collaboration by taking advantage of the opportunities.

Table 6. The WO Strategy (Weakness-Opportunity Strategy).

\begin{tabular}{|c|c|c|}
\hline Code & Indicator & Reference Code \\
\hline WO01 & Setting up standards (frameworks, models, and governance) for e-collaboration. & $\mathrm{C} 1-\mathrm{C} 2 \mathrm{~W} 2, \mathrm{~J} 16$ \\
\hline WO02 & Performing performance measurement and monitoring of e-collaboration. & J3, J6 \\
\hline WO03 & $\begin{array}{l}\text { Organizing routine outreach to change the local community's mind-set and/or officials who work with the } \\
\text { community about the importance to collaborate. }\end{array}$ & $\mathrm{J} 12, \mathrm{C} 6$ \\
\hline WO04 & Public and local knowledge sharing with fellow collaboration members. & W1 \\
\hline WO05 & Increasing trust among collaboration members. & $\mathrm{J} 3, \mathrm{~J} 5, \mathrm{~J} 9, \mathrm{~B} 2, \mathrm{~B} 4$ \\
\hline WO06 & Anticipating resource constraints by regional partnerships funding or network-based business partnerships funding. & B1, J17 \\
\hline WO07 & Preparing managers from the IS/IT side. & W1, J3, J6, C7, J18 \\
\hline WO08 & Preparing the younger generation who are more receptive to technology. & B1 \\
\hline WO09 & Preparing funding assistance from the government. & W2 \\
\hline WO10 & $\begin{array}{l}\text { Integrating ICTs into local knowledge and information systems to address locally identified knowledge gaps and } \\
\text { information problems. }\end{array}$ & W1 \\
\hline
\end{tabular}

\section{3-2-3- The ST Strategy (The Strength-Threat Strategy)}

The following statements identify what should be done so that the strengths of e-collaboration can minimize the threats.

Table 7. The ST Strategy (The Strength-Threat Strategy).

\begin{tabular}{|c|c|c|}
\hline Code & Indicator & Reference Code \\
\hline ST01 & Setting up a role to facilitate reconciliation between members. & $\mathrm{J} 12$ \\
\hline ST02 & Setting common goals and objectives and sharing them clearly among members. & $\mathrm{J} 3, \mathrm{~W} 2, \mathrm{~J} 6, \mathrm{~B} 1$ \\
\hline ST03 & Setting up an e-collaboration model that supports transparency. & $\mathrm{C} 1, \mathrm{~J} 19$ \\
\hline ST04 & Listening to the needs of rural communities. & $\mathrm{J} 2-\mathrm{J} 3, \mathrm{~B} 1, \mathrm{~J} 20$ \\
\hline ST05 & Empowering the involvement of villagers. & $\mathrm{C} 1, \mathrm{~B} 1$ \\
\hline
\end{tabular}

\section{3-2-4- The WT Strategy (The Weakness-Threats Strategy)}

The following statements identify what should be done to overcome the weaknesses and threats of e-collaboration. 
Table 8. The WT Strategy (Weakness-Threats Strategy).

\begin{tabular}{clcc}
\hline Code & & \multicolumn{1}{c}{ Indicator } & Reference Code \\
\hline WT01 & Preparing government bureaucracy (bureaucracy, mind-set, etc.) to support healthy e-collaboration. & W2, J8 & J12 \\
WT02 & Managing conflicts caused by cultural differences & J13 & W1, J17, J20 \\
WT03 & Carrying out network control to keep up with competitive developments among members. & W1 & W1 \\
WT04 & Doing more collaboration among local people. & \\
WT05 & Setting up institutions: decentralized control and capacity building for information resource management. & \\
WT06 & Anticipating information overload by preparing relevant and freely available information as public goods. &
\end{tabular}

\section{3-2-5- Fuzzy Delphi Method Analysis}

The questionnaire return response rate was $100 \%$ from eight experts. All 66 indicators in the eight constructs were given a Likert score from 1 to 5, on a scale from "strongly agree" to "strongly not agree." This Likert score is then converted into a fuzzy scale. The first prerequisite is fulfilled after the FDM analysis. The eight constructs have a threshold value of $d \leq 0.2$, even though several indicators in the construct have a threshold value of $d>0.2$. For the second prerequisite, five constructs had expert consensus less than $75 \%$, and three constructs had expert consensus greater than $75 \%$. The third prerequisite is used to sort the indicators by calculating the average fuzzy number. This construct's defuzzification value indicates that each indicator has exceeded the $\alpha$-cut value, which is 0.5 . All findings are summarized in Tables 9 and 10.

Table 9. Fuzzy Delphi Analysis for E-collaboration Factors.

\begin{tabular}{|c|c|c|c|c|c|c|}
\hline Construct & Indicator & $\begin{array}{c}\mathrm{d} \leq 0.2 \\
\text { Indicator }\end{array}$ & $\begin{array}{c}\mathrm{d} \leq 0.2 \\
\text { Expert Group }\end{array}$ & $\mathrm{d} \leq 0.2(\%)$ & $\begin{array}{c}\% \text { Expert Group } \\
\text { Consensus }\end{array}$ & Defuzzification \\
\hline \multirow{8}{*}{$\begin{array}{l}\text { Strengths - Porter's } \\
\text { Diamond Determinants }\end{array}$} & SFC1 & 0.187 & \multirow{8}{*}{0.156} & 85.71 & \multirow{8}{*}{74.29} & 0.714 \\
\hline & SFC3 & 0.150 & & 57.14 & & 0.571 \\
\hline & SDC1 & 0.177 & & 100.00 & & 0.685 \\
\hline & SRS1 & 0.148 & & 57.14 & & 0.657 \\
\hline & SRS2 & 0.148 & & 57.14 & & 0.657 \\
\hline & SRS3 & 0.173 & & 85.71 & & 0.685 \\
\hline & SRS4 & 0.173 & & 85.71 & & 0.685 \\
\hline & SFS1 & 0.102 & & 71.43 & & 0.628 \\
\hline \multirow{7}{*}{$\begin{array}{l}\text { Weaknesses - Porter's } \\
\text { Diamond Determinants }\end{array}$} & WDC1 & 0.150 & \multirow{7}{*}{0.186} & 100.00 & \multirow{7}{*}{68.57} & 0.285 \\
\hline & WRS1 & 0.237 & & 42.86 & & 0.571 \\
\hline & WRS2 & 0.075 & & 85.71 & & 0.628 \\
\hline & WRS3 & 0.125 & & 71.43 & & 0.657 \\
\hline & WFS1 & 0.224 & & 28.57 & & 0.628 \\
\hline & WFS2 & 0.187 & & 85.71 & & 0.514 \\
\hline & WFS3 & 0.299 & & 42.86 & & 0.542 \\
\hline \multirow{4}{*}{$\begin{array}{l}\text { Opportunities - Porter's } \\
\text { Diamond Determinants }\end{array}$} & OFC1 & 0.004 & \multirow{4}{*}{0.117} & 0.044 & \multirow{4}{*}{74.29} & 57.14 \\
\hline & OFS1 & 0.087 & & 0.087 & & 71.43 \\
\hline & OFS2 & 0.044 & & 0.044 & & 85.71 \\
\hline & OFS3 & 0.087 & & 0.087 & & 71.43 \\
\hline \multirow{6}{*}{$\begin{array}{l}\text { Threats - Porter's } \\
\text { Diamond Determinants }\end{array}$} & TFC1 & 0.169 & \multirow{6}{*}{0.124} & 0.495 & \multirow{6}{*}{71.43} & 71.43 \\
\hline & TRS1 & 0.175 & & 0.486 & & 71.43 \\
\hline & TRS2 & 0.087 & & 0.543 & & 71.43 \\
\hline & TRS3 & 0.044 & & 0.571 & & 85.71 \\
\hline & TRS4 & 0.087 & & 0.657 & & 71.43 \\
\hline & TFS1 & 0.181 & & 0.524 & & 57.14 \\
\hline
\end{tabular}


Ten indicators have a threshold value for construct $\mathrm{d} \leq 0.2$ and meet the first prerequisite to reach consensus in this construct. In this construct, four indicators with a threshold value of $\mathrm{d}>0.2$, WFC03, WRS01, WFS01, and WFS03, will be discussed further in the Discussion section.

Table 10. Fuzzy Delphi Analysis for Strategies.

\begin{tabular}{|c|c|c|c|c|c|c|}
\hline Construct & Indicator & $\begin{array}{c}\mathrm{d} \leq 0.2 \\
\text { Indicator }\end{array}$ & $\begin{array}{c}\mathrm{d} \leq 0.2 \\
\text { Expert Group }\end{array}$ & $\mathrm{d} \leq 0.2(\%)$ & $\begin{array}{c}\% \text { Expert Group } \\
\text { Consensus }\end{array}$ & Defuzzification \\
\hline \multirow{9}{*}{$\begin{array}{c}\text { Strength- } \\
\text { Opportunity (SO) }\end{array}$} & SO1 & 0.075 & \multirow{9}{*}{0.133} & 85.71 & \multirow{9}{*}{88.89} & 0.771 \\
\hline & $\mathrm{SO} 2$ & 0.150 & & 100.00 & & 0.714 \\
\hline & $\mathrm{SO} 3$ & 0.200 & & 85.71 & & 0.686 \\
\hline & $\mathrm{SO} 4$ & 0.125 & & 71.43 & & 0.743 \\
\hline & SO5 & 0.150 & & 100.00 & & 0.714 \\
\hline & SO6 & 0.150 & & 100.00 & & 0.714 \\
\hline & $\mathrm{SO} 7$ & 0.125 & & 71.43 & & 0.743 \\
\hline & SO8 & 0.150 & & 100.00 & & 0.686 \\
\hline & SO9 & 0.075 & & 85.71 & & 0.771 \\
\hline \multirow{10}{*}{$\begin{array}{c}\text { Weakness- } \\
\text { Opportunity (WO) }\end{array}$} & WO1 & 0.150 & \multirow{10}{*}{0.168} & 100.00 & \multirow{10}{*}{85.71} & 0.686 \\
\hline & WO2 & 0.150 & & 100.00 & & 0.686 \\
\hline & WO3 & 0.294 & & 28.57 & & 0.638 \\
\hline & WO4 & 0.150 & & 100.00 & & 0.686 \\
\hline & WO5 & 0.125 & & 71.43 & & 0.657 \\
\hline & WO6 & 0.150 & & 100.00 & & 0.686 \\
\hline & WO7 & 0.150 & & 100.00 & & 0.686 \\
\hline & WO8 & 0.200 & & 85.71 & & 0.686 \\
\hline & WO9 & 0.162 & & 71.43 & & 0.571 \\
\hline & WO10 & 0.150 & & 100.00 & & 0.686 \\
\hline \multirow{5}{*}{$\begin{array}{l}\text { Strength-Threat } \\
\text { (ST) }\end{array}$} & ST01 & 0.075 & \multirow{5}{*}{0.125} & 85.71 & \multirow{5}{*}{74.29} & 0.629 \\
\hline & ST02 & 0.150 & & 100.00 & & 0.714 \\
\hline & ST03 & 0.125 & & 71.43 & & 0.743 \\
\hline & ST04 & 0.125 & & 71.43 & & 0.743 \\
\hline & ST05 & 0.150 & & 100.00 & & 0.714 \\
\hline \multirow{6}{*}{$\begin{array}{l}\text { Weakness-Threats } \\
\text { (WT) }\end{array}$} & WT01 & 0.150 & \multirow{6}{*}{0.148} & 100.00 & \multirow{6}{*}{71.43} & 0.686 \\
\hline & WT02 & 0.200 & & 85.71 & & 0.686 \\
\hline & WT03 & 0.175 & & 42.86 & & 0.600 \\
\hline & WT04 & 0.087 & & 71.43 & & 0.600 \\
\hline & WT05 & 0.125 & & 71.43 & & 0.743 \\
\hline & WT06 & 0.150 & & 57.14 & & 0.571 \\
\hline
\end{tabular}

\section{4- Discussion}

\section{4-1-e-Collaboration Success Factors}

FDM analysis for the first construct (Strengths - Porter's Diamond Determinants) meets the threshold standard where the value is $d \leq 0.2$ but does not meet the $75 \%$ expert-group consensus target because the value is $74.29 \%$. In this construct, the consensus was still obtained from the expert panel, but the results did not meet the standards because some factors were considered to be inappropriate. Researchers took the indicator with the lowest consensus value, e-collaboration: strengthening online marketing based on word of mouth (WoM), and asked the experts for more input. One expert stated that the context of e-collaboration is not only for online marketing but rather, how to usefully enhance technology to improve the tourism experience. One indicator received $100 \%$ expert-group consensus: e-collaboration can take advantage of an open and modern technology platform to improve the economy in rural areas. The platform could be considered an application that supports the integration of producers and consumers without mediators [36].

E-collaboration also provides an opportunity for members to conduct business activities better, that is, quickly accessing the information needed and carrying out administrative activities smoothly and transparently [36, 43]. Thus, 
e-collaboration can help a village manage its tourism activities efficiently and effectively. In addition to acquiring benefits for internal activities, members will share knowledge, collaborate in developing a product, and market it together by collaborating $[16,37,56]$. The majority of experts also agreed that e-collaboration would significantly help SMEs in remote locations. E-collaboration also facilitates local entrepreneurs' involvement to increase the quality and quantity of their business [16] because they will achieve a stronger market position and help each other. One expert also said that in these conditions, collaboration must be directed to digital or electronic formats. The next step, according to that expert, is how to collaborate and coordinate with various stakeholders using information technology. Studies show knowledge sharing is an important factor in e-collaboration. Knowledge in one person or one business is growing, accommodated in e-collaboration, and used to solve common problems in the tourism business [48]. The ecollaboration concept is very supportive of e-commerce transactions in the context of online product sales [39]. The current study shows that SMEs' adoption of e-commerce is still relatively low and slow, especially for tourism businesses in rural areas. Several limitations hinder the adoption of e-commerce for tourism SMEs: limited resources, business environment, and attributes related to IT preparation.

The FDM analysis results for the second construct on the success factors of e-collaboration for rural tourism, the elements included in the Weakness dimension mapped to each determinant in the Porter's Diamond model, fulfills the first prerequisite to reach consensus. In this construct, four indicators related to culture, e-collaboration governance, and collaboration models have a threshold value of $d>0.2$. The researcher further investigated these findings by conducting interviews with experts and reviewing relevant references. All sources agreed that cultural elements need to be considered in an IT adoption because they may become obstacles if not appropriately managed. In general, it is expected that e-collaboration will become a framework or tool that is inherent in society. One study stated that the influence of culture in adopting new technology would differ in each country. In developing countries, IT adoption shows that social networks are significant in building social and emotional cues for adoption, especially for people in rural areas who still have concrete collectivist elements [64]. From a technical point of view, the government prepares the infrastructure in stages, but how people are willing to share, cooperate, and see this activity as a collaboration and not competition is a very significant social aspect that needs to be studied more deeply. The experts also agreed that culture needs to be developed to see beyond this effort as a one- or two-year project. The infrastructure can be used in the long term and even over decades, but how to perform and manage activities on this infrastructure will be a significant challenge. Expert opinions differ regarding how COVID-19 and its impact on rural communities will shift the paradigm. Several previous studies stated that cultural differences were an obstacle to technology acceptance in rural areas $[15,36,51,57]$ negatively affected by COVID-19. The paradigm shifts occurred quickly and can be thought of as a "blessing in disguise" because the pandemic made everyone think of the use of IT at the same time, including rural communities. Without conscious attention, a shift that had been difficult for people in rural areas to consider ultimately united people in wanting to collaborate digitally.

Another major concern in realizing e-collaboration is the lack of IT capability in rural areas [42, 45], including IT infrastructure and digital literacy. The lack of IT capability addresses IT standards, models, or governance in an ecollaboration that does not yet exist [36, 57]. Learning from the current conditions if a crisis occurs, governance is critical for tourism resilience and recovery. Public-private partnerships and various collaboration models have been strengthened by increasing stakeholders' participation at multiple administration levels and private sectors in the tourism industry in some countries. Other resource constraints that need to be adequately identified are human resources to operate IT and IT procurement and maintenance budgets [36, 39, 43, 47, 50, 53, 56, 57]. E-collaboration can reduce costs in acquiring knowledge and innovation. However, companies must also incur transaction costs when collaborating, which can also be decreased if collaborators have high trust and a fundamental understanding of sharing resources. Finally, collaboration cannot take place if there is no element of trust among stakeholders [15, 16, 37,48, $50,56,57,60]$.

Ten indicators have a threshold value of $\mathrm{d} \leq 0.2$ in the FDM analysis results for the third construct (Opportunities Porter's Diamond Determinants) and fulfill the first prerequisite to reach consensus. However, in the second prerequisite, the $75 \%$ expert-group consensus for $d \leq 0.2$ is $74.29 \%$. The consensus was still obtained from the expert panel in this construct, but the results did not meet the standards. One expert is not sure that this factor, "ecollaboration supports efforts to prepare product diversity," is an opportunity for e-collaboration for rural tourism development. In interviews, participants stated that the operational definition of e-collaboration was not adequately explained in the questionnaire, and this lack of clarity caused some doubt when responding to the questionnaire. The questionnaire also does not indicate the ultimate goal of the study, whether the end would be to build a platform or a model, so the product diversity factor was identified as an opportunity. A tourist spot often has a "best time" to visit. Collaboration members need to provide other products and tourist attractions to maintain tourism continuity throughout the year. Thus, e-collaboration is not only a platform but also a business with a new management method $[46,48]$. Markets can change quickly, and the level of competition is high enough to encourage a business to find new ways to maintain its business $[45,51,56]$. E-collaboration also provides entrepreneurs opportunities to build their digital business content, products, and services and continuously innovate [16, 36]. 
Next is the fourth construct (Threats - Porter's Diamond Determinants), which is included in the Threat dimension, mapped in each determinant of Porter's Diamond model. The FDM analysis results on this construct have met the first prerequisite to reach a consensus threshold value of $\mathrm{d} \leq 0.2$. In this construct, the consensus is still obtained, but the 75\% expert-group consensus has not been fulfilled (71.43\%) due to differences of opinion about whether ecollaboration will cause information overload. This factor may occur, but in the initial stage, e-collaboration focuses on functionality because e-collaboration is expected to be a post-pandemic rural tourism recovery strategy.

Although the opportunities and benefits of e-collaboration have been explored in detail, it is important to be vigilant about obstacles and even threats. Focusing too much on the use of IT can neglect communities and institutions that previously had a more significant role in local information and knowledge systems [47] or even exacerbate the digital divide in that society [36]. Parties who feel they have better capability could dominate e-collaboration, making other members dependent on one party $[43,65]$. There is also a concern that specific individuals might organize or lead associations solely for their own benefit [16]. IT implementation tends to buy technology, so dependence on vendors is relatively high. The knowledge gap between collaborators is another opportunity for conflict in an ecollaboration. Some of the problems and concerns arise from the public reaction to the current crisis: the emergence of a new digital divide, issues of data security and privacy, and ethical use of technology at all levels of the tourism industry due to the intensive use of IT $[65,66]$. Meanwhile, the problem of the digital divide itself has existed for a long time in rural areas [67].

\section{4-2-The E-collaboration Strategies}

Of the four constructs in this section, three have complete consensus from experts (SO strategy, WO strategy, and ST strategy) because they fulfill three prerequisites of FDM analysis (Table 10). Meanwhile, one other construct, the WT strategy, still achieves consensus but does not meet the $75 \%$ expert-group consensus because there are differences of opinion among experts related to the culture, which have been widely discussed at the beginning of this paper.

SO strategies take advantage of opportunities by maximizing a company's internal strengths, one of which is the support and management commitment. This strategy is closely related to other techniques because it will increase ongoing e-collaboration activities, affecting rural tourism's sustainable management. Loyalty is an inseparable part of a long-term relationship and is described as a lasting intention from all collaboration members to maintain a relationship that is considered valuable and is a sustainable competitive advantage for the company [63]. All collaboration members must have the exact definition of the problem they face: to recover businesses that collapsed due to physical restriction policies. It is necessary to pay attention to several factors, including leadership, goals, communication, time availability, funding, and collaboration with local governments to realize e-collaboration for sustainable tourism villages [68]. Previous studies have shown that it is difficult to move to a sustainable tourism model. IT-based collaborative activities are seen as an opportunity to transition to such a sustainable tourism model.

Collaborative activity is driven by the same values, norms, knowledge, and views, attracting sustainable tourism [69]. However, e-collaboration activities must still attend to social aspects that play a significant role in ongoing collaboration activities. The successful implementation of IT is more influenced by social factors, one of which is culture, than technological aspects [70]. In responding to disasters, effective inter-agency collaboration is essential for tourism recovery efforts. The tourism industry is problematic because it involves many stakeholders. To help reduce the harmful effects of disasters, tourism needs ongoing efforts to maintain and develop collaborative relationships between stakeholders $[14,71]$. E-collaboration is also expected to become a collaborative network and a joint effort carried out for the long term to meet individual and shared goals. Sustainable tourism in rural areas utilizing this IT can be a strategy to survive for an indefinite period if developed with good planning [72], including planning for when a disaster or crisis occurs. Future research related to IT in tourism should be focused on increasing innovation, sustainable tourism, and improving the welfare and quality of life of rural communities. Possible research topics are related to innovative e-collaboration governance and resilience, especially in response to an unprecedented crisis caused by the COVID-19 pandemic [3]. The speed of recovery would also be interesting to research.

Competitive advantage is no longer simply relying on natural resources but is also driven by integrating IT and innovation in a tourism destination [73]. E-collaboration for tourism is seen as harnessing IT as a strategic tool to develop rural tourism. E-collaboration can be made on a digital platform to share resources or knowledge and collaborate with stakeholders in the tourism industry. One example is virtual tours. Virtual tourism offerings were somewhat underdeveloped prior to the pandemic, making them ideal for today's tourism businesses to develop business models and offer new digital-based products [74]. In digital tourism products, several business actors can collaborate to improve the experience of traveling virtually. An excellent virtual tourism product needs support from various parties, including the government, to train and expand skills development programs [73].

E-collaboration initiatives are not solely focused on online marketing activities but are also a series of initiatives to build a relationship or network of tourism association members (whether based on region, market or function) and local communities. Structured collaboration forms are encouraged to prepare sustainable tourism in rural areas [42]. Another goal is to create new tourism services or experiences and customize tourism products to increase business 
continuity and improve visitors' experiences [16]. E-collaboration will increase the substantial involvement of tourism associations with a significant focus on product development and not only numerous attractions [56].

WO strategy must be carried out to overcome the weaknesses of e-collaboration by taking advantage of opportunities related to limited information technology resources and their management. Governance offers valuable guidance for the goal of collaborating electronically. In e-collaboration governance, actors' roles will be regulated, such as preparing electronic media for dialogue, building trust, understanding common goals, institutional arrangements, and leadership [37]. In developing a strategy for IT-based initiatives, apart from defining the actors involved, it is also necessary to emphasize the importance of actor commitment in the process of interaction and negotiation, alignment of interests between actors, and their ability to carry out active roles [75]. In a collaborative activity, leadership produces visible and tangible results, especially in difficult times like recovery from the effects of the COVID-19 pandemic. In addition to governance, it is also necessary to prepare an e-collaboration framework. A framework can maintain the collaboration by minimizing knowledge gaps among stakeholders, reducing conflict of benefits among stakeholders, and maintaining long-term collaboration [51]. The framework is also helpful in providing a better understanding of how e-collaboration can be used to build adaptive capacity for rural tourism in a crisis. When developing strategies to reduce the risk of conflict, it is necessary to know and understand who the potential collaborators are and potential problems and targets [54].

E-collaboration is based on an evolutionary partnership model, through clear stages: antecedents, problem sets, direction setting, arrangement, and results, which various institutions will later facilitate in rural areas in both developed or developing countries [6]. Analysis and monitoring are necessary for e-collaboration to run according to its objectives during the collaboration process. Monitors can include actors' commitment from various sectors to a common tourism development agenda and structured forms of coordination to promote sustainable tourism in rural areas [42]. Based on expert experience (in general), collaboration awareness is driven by the potential cost efficiency and benefits of a network [56]. Most of the tourism industry businesses are small businesses that already have their market. However, when a crisis occurs, it becomes tough for them to maintain a business or open a new business. To answer the challenges and at the same time take advantage of opportunities for tourism SMEs, it is necessary to encourage the development of cooperative relationships by using similar or complementary resources so that collaborative activities can strengthen their competence [76].

The government's role in e-collaboration activities is to support, encourage, assist, and foster collaboration. The government is also expected to be the driving force, providing funding (e.g., grants or low-interest loans) and business referrals, including policy [77]. Governance and monitoring can be prepared so that e-collaboration activities can produce results following its objectives. The government should think of the bigger picture and have an open and transparent future vision to encourage collaboration [56]. Infrastructure, both physical and IT, is the government's responsibility, which can be worked on in partnership with private companies. Currently, the Indonesian government has prepared a development unit from the Telecommunication and Information Accessibility Agency under the Ministry of Communication and Information to prepare Internet access as a foundation for e-collaboration activities for 83,218 villages and wards throughout Indonesia. This access will be implemented in stages. Until now, the portrait of infrastructure in Indonesia can be seen by the availability of sufficient backbone, middle mile, and last-mile network access, although there are still limitations considering Indonesia has 17,500 islands. The strategy combines terrestrial technology with non-terrestrial technology and mobile broadband with fixed broadband to provide Internet access to more islands.

ST Strategy is a strategy that must be done so that the strengths of e-collaboration can minimize the threat. Citizen involvement is extensive in this strategy. A collaborative approach involves residents to maintain a high quality of life for residents and succeed in an increasingly competitive market. The collaborative process should listen to people's opinions on how they perceive their well-being and how tourism affects this [78]. The tourism industry involves interactions between organizations, people, and events in various subsystems. This interconnected system's complexity is a challenge for researchers in the tourism sector to prepare a post-crisis recovery mechanism [79]. With this mechanism, the tourism industry will be more resilient and have a crisis recovery strategy. In a tourism activity, failure to empower and involve the community in tourism management endangers the tourism ecosystem's long-term survival and the people in the area [57]. Locality and cultural dimensions are of concern in developing collaborative initiatives that utilize information technology [16]. COVID-19 is a valuable opportunity to rethink and reorganize tourism management centered on communities and local communities [80].

WT strategies are any strategies that must be done to overcome the weaknesses and threats of e-collaboration, one of which is culture. The challenge of collaboration is knowing how to start working together and identify who will take the initial initiative. It is also necessary to create a culture where collaboration becomes more natural so that ecollaboration members can interact online in an open, informal, and transparent manner. It is hoped that this can increase a culture of sharing and increase trust among collaboration members. Goodwill of individuals involved in collaboration was identified as an initial goal of e-collaboration [81], followed by defining clear goals and roles for each member. Collaboration frameworks must be community centered [80]. The part that individuals have in the 
community is crucial in e-collaboration. These roles will vary and involve various stakeholders, such as small business owners, local authorities, NGOs, and even community volunteers. Related to conflict, several things that must be done to overcome friction in e-collaboration are preparing a planned collaboration process, designing communication, building trust, and preparing collaborative leadership [42]. Some steps must be emphasized in the preparation process: commitment to the process, sharing understanding, process clarification, and stakeholder preparation for a negotiation. The sub-process at the sharing understanding stage includes defining clear goals, defining common problems, and desired goals. The appointment of a person or party who acts as a facilitator in e-collaboration is needed to anticipate future conflicts.

The e-collaboration strategy approach in rural tourism emphasizes the socio-economic contribution to society by encouraging non-hierarchical and flexible partnerships between the government (public) and non-government (business and community) sectors to mobilize the local community, cultural and natural resources [6]. The structuring or e-collaboration implementation stage for rural tourism requires constructing suitable structures to institutionalize tourism and rural development processes to maximize local rural communities' socio-economic contribution. The partnership that is built must be equal between government and non-government stakeholders concerning decisionmaking.

\section{5- Conclusion}

There is a general agreement between literature and experts that it is imperative to understand better the strategic value of e-collaboration activities in rural tourism. Rural tourism development is currently an answer to the multiplier effect of the crisis conditions due to COVID-19. E-collaboration will play an essential role in ensuring business competitiveness and supporting the sustainability of rural tourism activities in the future. Collaborative partnerships harnessing IT are governance mechanisms of particular relevance for addressing skills, managerial, infrastructure limitations, and innovation deficiencies. The area of investigation in this research is Indonesia because it represents a country with much potential for rural tourism. The methodology used can be replicated in a wider context to develop rural tourism in other developing countries. This research can be used as a reference for the recovery of rural tourism in developing countries with characteristics similar to Indonesia.

However, this study's contribution has several limitations that open opportunities for new research. First, the local government's perspective is considered a representation of the citizens' point of view, so there may be differences. Future research is expected to directly involve citizens and consider collaborative research with the government, tourism industry, universities, media, and local communities. Second, the e-collaboration research conducted thus far has not explored its benefits for rural tourism, so the references used as material in this literature study are limited. Indicators that do not reach consensus are due to a gap between research time and the massive acceleration of digitalization since COVID-19. Given that e-collaboration research for rural tourism is relatively new, this paper is a literature study that highlights the success factors and implementation strategies to support future research.

\section{6- Declarations}

\section{6-1-Author Contributions}

Methodology, formal analysis, writing - original draft preparation, M.P.; supervision, B.P.; writing - review and editing, B.P., F.P.S. and F.S. All authors have read and agreed to the published version of the manuscript.

\section{6-2-Data Availability Statement}

The data presented in this study are available in article.

\section{6-3- Funding}

This research received PUTI grant funding from the Universitas Indonesia with Contract Number: NKB4381/UN2.RST/HKP.05.00/2020.

\section{6-4- Conflicts of Interest}

The authors declare that there is no conflict of interests regarding the publication of this manuscript. In addition, the ethical issues, including plagiarism, informed consent, misconduct, data fabrication and/or falsification, double publication and/or submission, and redundancies have been completely observed by the authors.

\section{7- References}

[1] UNWTO. “Tourism News Release Impact of Covid-19 on Global Tourism Made,” no. JULY 2020 (2020): 33-34.

[2] Gössling, Stefan, Daniel Scott, and C. Michael Hall. "Pandemics, Tourism and Global Change: a Rapid Assessment of COVID19.” Journal of Sustainable Tourism 29, no. 1 (April 27, 2020): 1-20. doi:10.1080/09669582.2020.1758708. 
[3] Yang, Yang, Hongru Zhang, and Xiang Chen. "Coronavirus Pandemic and Tourism: Dynamic Stochastic General Equilibrium Modeling of Infectious Disease Outbreak.” Annals of Tourism Research 83, (2020). doi:10.1016/j.annals.2020.102913.

[4] Higgins-Desbiolles, Freya. "The 'War over Tourism': Challenges to Sustainable Tourism in the Tourism Academy after COVID-19.” Journal of Sustainable Tourism (2020), 1-19. doi:10.1080/09669582.2020.1803334.

[5] Revindo, Mohamad D., Syahda Sabrina, and Muhamad Sowwam. "Impact of the Covid-19 Pandemic on Indonesian Tourism: Challenges, Outlook and Policy Response" (2020).

[6] Keyim, P. “Collaboration and Rural Development in a Tourism Context.” Tourism Development, no. October (2015): 161-76.

[7] Perkins, Rachel, and Catheryn Khoo-Lattimore. "Friend or Foe: Challenges to Collaboration Success at Different Lifecycle Stages for Regional Small Tourism Firms in Australia.” Tourism and Hospitality Research 20, no. 2 (March 26, 2019): $184-197$. doi:10.1177/1467358419836719.

[8] Wilson, Suzanne, Daniel R. Fesenmaier, Julie Fesenmaier, and John C. Van Es. "Factors for Success in Rural Tourism Development.” Journal of Travel Research 40, no. 2 (2001): 132-38. doi:10.1177/004728750104000203.

[9] Kolaczek, Grzego rz, Adam Turowiec, Dominik Kasprzak, and Witold Holubowicz. "e-Collaboration Platform for the Development of Rural Areas and Enterprises." 2008 International Multiconference on Computer Science and Information Technology (October 2008): 397-401. doi:10.1109/imcsit.2008.4747272.

[10] Rabadán-Martín, Inmaculada, Francisco Aguado-Correa, and Nuria Padilla-Garrido. "Facing New Challenges in Rural Tourism: Signaling Quality via Website." Information Technology and Tourism 21, no. 4 (2019): 559-76. doi:10.1007/s40558-019-00157-y.

[11] Werthner, Hannes, Aurkene Alzua-Sorzabal, Lorenzo Cantoni, Astrid Dickinger, Ulrike Gretzel, Dietmar Jannach, Julia Neidhardt, et al. "Future Research Issues in IT and Tourism: A Manifesto as a Result of the JITT Workshop in June 2014, Vienna.” Information Technology and Tourism 15, no. 1 (2015): 1-15. doi:10.1007/s40558-014-0021-9.

[12] Meiliana, Devita Irmanti, Mochamad Rizal Hidayat, Nur Viani Amalina, and Dewi Suryani. "Mobile Smart Travelling Application for Indonesia Tourism.” Procedia Computer Science 116, (2017): 556-63. doi:10.1016/j.procs.2017.10.059.

[13] Hadzic, Miroljub, and Petar Pavlovic. "Rethinking Strategy for SMEE Support in the Light of the Entrepreneurial Ecosystem." Emerging Science Journal 3, no. 6 (December 1, 2019): 389-394. doi:10.28991/esj-2019-01201.

[14] Jiang, Yawei, and Brent W. Ritchie. "Disaster Collaboration in Tourism: Motives, Impediments and Success Factors.” Journal of Hospitality and Tourism Management 31, (2017): 70-82. doi:10.1016/j.jhtm.2016.09.004.

[15] Burgess, Lois, Carole Alcock, and Michael Jones. "ECollaboration Among Tourism SMEs: Why It Works, Why It Doesn't An Empirical Study from Australia” (2012). doi:10.1017/CBO9781107415324.004.

[16] Deuchar, C., and S. Milne. "Rural Tourism and Small Business Networks in Mountain Areas: Integrating Information Communication Technologies (ICT) and Community in Western Southland, New Zealand.” Mountain Tourism: Experiences, Communities, Environments and Sustainable Futures (2016): 280-289. doi:10.1079/9781780644608.0280.

[17] Bouras, Christos, Eri Giannaka, and Thrasyvoulos Tsiatsos. "E-Collaboration Concepts, Systems, and Applications." Encyclopedia of Internet Technologies and Applications, (2007): 165-71. doi:10.4018/978-1-59140-993-9.ch024.

[18] Kock, Ned, Robert Davison, Raul Wazlawick, and Rosalie Ocker. "E-collaboration: A Look at Past Research and Future Challenges.” Journal of Systems and Information Technology 5, no. 1 (June 2001): 1-8. doi:10.1108/13287260180001059.

[19] Winarsih, Maya Indriastuti, and Khoirul Fuad. "Impact of Covid-19 on Digital Transformation and Sustainability in Small and Medium Enterprises (SMEs): A Conceptual Framework.” Advances in Intelligent Systems and Computing (June 11, 2020): 471-476. doi:10.1007/978-3-030-50454-0_48.

[20] Chaffey, Dave. Digital Business and E-Commerce Management: Strategy, Implementation and Practice. Vol. 6 (2015). Pearson.

[21] Bratko, Artem, Dmytro Oleshko, Anton Datskov, Valerii Vychavka, Oleksandr Olytskyi, and Ihor Balytskyi. "Use of the SWOT Analysis in the Field of National Security Planning.” Emerging Science Journal 5, no. 3 (June 1, 2021): $330-337$. doi:10.28991/esj-2021-01280.

[22] Hadiansyah, Hary, Betty Purwandari, Riri Satria, and Satrio Baskoro Yudhoatmojo. "Social Media Strategies for Public Diplomacy: A Case Study in the Ministry of Foreign Affairs of the Republic of Indonesia." Proceedings of the 2nd International Conference on Informatics and Computing, ICIC 2017 2018-January, (2018): 1-5. doi:10.1109/IAC.2017.8280636.

[23] Gurel, Emet, and Merba Tat. "SWOT Analysis: A Theoretical Review." The Journal of International Social Research 10, no. 51 (2017): 1-14. 
[24] Moher, David, Alessandro Liberati, Jennifer Tetzlaff, and Douglas G. Altman. "Reprint—Preferred Reporting Items for Systematic Reviews and Meta-Analyses: The PRISMA Statement.” Physical Therapy 89, no. 9 (September 1, 2009): 873-880. doi:10.1093/ptj/89.9.873.

[25] Manakandan, Sujith Kumar, Rosnah Ismai, Mohd Ridhuan Mohd Jamil, and Priya Ragunath. "Pesticide Applicators Questionnaire Content Validation: A Fuzzy Delphi Method.” Medical Journal of Malaysia 72, no. 4 (2017): 228-35.

[26] Sensuse, Dana Indra, Betty Purwandari, and Puji Rahayu. "Defining E-Portofolio Factor for Competency Certification Using Fuzzy Delphi Method.” Turkish Online Journal of Educational Technology - TOJET 17, no. 2 (2018): 25-33.

[27] Adnan, Hafizh Rafizal, Achmad Nizar Hidayanto, Betty Purwandari, Meidi Kosandi, Widia Resti Fitriani, and Sherah Kurnia. "Multi-Dimensional Perspective on Factors Influencing Technology Adoption for Open Government Initiatives: A Systematic Literature Review." 2019 International Conference on Advanced Computer Science and Information Systems, ICACSIS 2019 (2019). doi:10.1109/ICACSIS47736.2019.8979924.

[28] Handayani, Putu Wuri, Achmad Nizar Hidayanto, and Indra Budi. "User Acceptance Factors of Hospital Information Systems and Related Technologies: Systematic Review." Informatics for Health and Social Care 43, no. 4 (2018): 401-26. doi:10.1080/17538157.2017.1353999.

[29] Kareen, Pamela, Betty Purwandari, Iik Wilarso, and M. Octaviano Pratama. "E-Commerce Adoption in SME: A Systematic Review." 2018 6th International Conference on Cyber and IT Service Management, CITSM 2018, (2019): 1-7. doi:10.1109/CITSM.2018.8674285.

[30] Mishbah, Muhammad, Betty Purwandari, and Dana Indra Sensuse. "Systematic Review and Meta-Analysis of Proposed Smart Village Conceptual Model: Objectives, Strategies, Dimensions, and Foundations.” 2018 International Conference on Information Technology Systems and Innovation, ICITSI 2018 - Proceedings (2018). doi:10.1109/ICITSI.2018.8696029.

[31] Smit, A. J. "The Competitive Advantage of Nations: Is Porter's Diamond Framework a New Theory That Explains the International Competitiveness of Countries? | Southern African Business Review.” Southern African Business Review 14, no. 1 (2010): 105-30.

[32] Esen, Saban, and Hande Uyar. "Examining the Competitive Structure of Turkish Tourism Industry in Comparison with Diamond Model.” Procedia - Social and Behavioral Sciences 62, (2012a: 620-27. doi:10.1016/j.sbspro.2012.09.104.

[33] Grant, Robert M. "Porter's 'competitive advantage of nations': an assessment." Strategic management journal 12, no. 7 (1991): 535-548. doi:10.1016/10.1002/smj.4250120706.

[34] Saffie, N. Amira M., Nur'Amirah Mohd Shukor, and Khairul A. Rasmani. "Fuzzy Delphi Method: Issues and Challenges.” In 2016 International Conference on Logistics, Informatics and Service Sciences (LISS) (2016). doi:10.1109/liss.2016.7854490.

[35] Hsu, Yu Lung, Cheng Haw Lee, and V. B. Kreng. "The Application of Fuzzy Delphi Method and Fuzzy AHP in Lubricant Regenerative Technology Selection.” Expert Systems with Applications 37, no. 1 (2010): 419-25. doi:10.1016/j.eswa.2009.05.068.

[36] Bremser, Christian, Gunther Piller, and Franz Rothlauf. "How Smart Cities Explore New Technologies." In International Conference on Business Informatics Research, 1-15 (2019). doi:10.1007/978-3-030-31143-8_1.

[37] Bichler, Bernhard Fabian, and Magdalena Lösch. "Collaborative Governance in Tourism: Empirical Insights into a Community-Oriented Destination.” Sustainability 11, no. 23 (November 26, 2019): 6673. doi:10.3390/su11236673.

[38] Zeiller, Michael, and Bettina Schauer. "Adoption, Motivation and Success Factors of Social Media for Team Collaboration in SMEs.” ACM International Conference Proceeding Series (2011). doi:10.1145/2024288.2024294.

[39] Abou-Shouk, Mohamed, Wai Mun Lim, and Phil Megicks. "E-Commerce and Small Tourism Businesses in Developing Countries: Drivers versus Boundaries of Adoption." Tourism Planning and Development 10, no. 3 (2013): $249-66$. doi:10.1080/21568316.2012.747983.

[40] Pons-Morera, C., L. Cano's-Daro's, and I. Gil-Pechuan. "A Model of Collaborative Innovation between Local Government and Tourism Operators.” Service Business 12, (2018): 143-68. doi:10.1007/s11628-017-0341-x.

[41] Lock, Jennifer V., and Petrea Redmond. "Working Collaboratively on the Digital Global Frontier." Handbook of Research on Electronic Collaboration and Organizational Synergy (2010): 177-191. doi:10.4018/978-1-60566-106-3.ch012.

[42] Chiodo, Emilio, Héctor Luis Adriani, Fernando Pablo Navarro, and Rita Salvatore. "Collaborative Processes and Collective Impact in Tourist Rural Villages-Insights from a Comparative Analysis between Argentinian and Italian Cases.” Sustainability (Switzerland) 11, no. 2 (2019). doi:10.3390/su11020432.

[43] Bremser, Christian, Gunther Piller, and Markus Helfert. "Technology Adoption in Smart City Initiatives: Starting Points and Influence Factors." SMARTGREENS 2019 - Proceedings of the 8th International Conference on Smart Cities and Green ICT Systems, (2019): 70-79. doi:10.5220/0007702700700079. 
[44] Hamari, Juho, Mimmi Sjöklint, and Antti Ukkonen. "The Sharing Economy: Why People Participate in Collaborative Consumption." Journal of the Association for Information Science and Technology 67, no. 9 (2016): $2047-59$. doi:10.1002/asi.23552.

[45] Fachrunnisa, Olivia, Mutamimah, and Gunawan. "Digital Collaboration Network for SMEs: Awareness of ICT and Perceived Outcome." Proceedings - 2013 7th International Conference on Complex, Intelligent, and Software Intensive Systems, CISIS 2013 (2013), 40-46. doi:10.1109/CISIS.2013.17.

[46] Jeon, Rara, and Daniel Dagravel. "Open Innovation, R\&D Collaboration and Global Strategy in High-Tech SMEs: Focused on R\&D Collaboration Mode.” In Proceedings of the 5th International Conference on Innovation and Entrepreneurship ICIE 2017, (2017): 52-60.

[47] Chapman, Robert, and Tom Slaymaker. "ICTs and Rural Development: Review of the Literature, Current Interventions and Opportunities for Action" (2002).

[48] Brunetto, Yvonne, and Rod Farr-Wharton. "The moderating role of trust in SME owner/managers' decision - making about collaboration." Journal of Small Business Management 45, no. 3 (2007): 362-387. doi:10.1111/j.1540-627X.2007.00218.x.

[49] Johson, Abbie-Gayle, Jilian M. Rickly, and Scott McCabe. "Relational Factors That Influence Multi-Stakeholder Engagement in Inter-Organisational Collaboration: An Examination of Tourism Supplier Engagement in Smart Tourism." In Proceedings of the ENTER2020, (2020): 11-15.

[50] Kennedy, Kim, and Toby William. “Collaboration for Rural Business Growth.” Rural Business (2012).

[51] Ngo, Tramy, Rob Hales, and Gui Lohmann. "Collaborative Marketing for the Sustainable Development of Community-Based Tourism Enterprises: A Reconciliation of Diverse Perspectives.” Current Issues in Tourism 22, no. 18 (2019): $2266-83$. doi:10.1080/13683500.2018.1446919.

[52] Vinod Kumar, T. M., and Bharat Dahiya. "Smart Economy in Smart Cities." Advances in 21st Century Human Settlements (August 26, 2016): 3-76. doi:10.1007/978-981-10-1610-3_1.

[53] Docherty, Iain, Stuart Gulliver, and Philip Drake. "Exploring the Potential Benefits of City Collaboration.” Regional Studies 38, no. 4 (2004): 445-56. doi:10.1080/03434002000213950.

[54] Sigala, Marianna, and Richard N.S. Robinson, "Wine Tourism Destination Management and Marketing" (2019). doi:10.1007/978-3-030-00437-8.

[55] Duglio, Stefano, Alessandro Bonadonna, Marilisa Letey, Giovanni Peira, Laura Zavattaro, and Giampiero Lombardi. "Tourism Development in Inner Mountain Areas-the Local Stakeholders' Point of View through a Mixed Method Approach." Sustainability (Switzerland) 11, no. 21 (2019). doi:10.3390/su11215997.

[56] Tremblay, Pascal, and Aggie Wegner. "The Costs and Implications of Inter-Firm Collaboration in Remote Area Tourism", (2009).

[57] Wondirad, Amare, Denis Tolkach, and Brian King. "Stakeholder Collaboration as a Major Factor for Sustainable Ecotourism Development in Developing Countries.” Tourism Management 78, (2020). doi:10.1016/j.tourman.2019.104024.

[58] Cai, Jian. "A Social Interaction Analysis Methodology for Improving E-Collaboration over the Internet." Electronic Commerce Research and Applications 4, no. 2 (2005): 85-99. doi:10.1016/j.elerap.2004.10.007.

[59] Nezakati, Hossein, Asra Amidi, Yusmadi Yah Jusoh, Shayesteh Moghadas, Yuhanis Abdul Aziz, and Roghayeh Sohrabinezhadtalemi. "Review of Social Media Potential on Knowledge Sharing and Collaboration in Tourism Industry." Procedia - Social and Behavioral Sciences 172, (2015): 120-25. doi:10.1016/j.sbspro.2015.01.344.

[60] Ma, Caiwei. "E-Collaboration: A Universal Key to Solve Fierce Competition in Tourism Industry?" International Business Research 1, no. 4 (February 9, 2009). doi:10.5539/ibr.v1n4p65.

[61] Hardy, Cynthia, Nelson Phillips, and Thomas B. Lawrence. "Resources, Knowledge and Influence: The Organizational Effects of Inter Organizational Collaboration." Journal of Management Studies 40, no. 2 (2003): 321-47. doi:10.1111/14676486.00342 .

[62] Thomson, Ann Marie, and James L. Perry. "Collaboration Processes: Inside the Black Box.” Public Administration Review 66, no. s1 (December 2006): 20-32. doi:10.1111/j.1540-6210.2006.00663.x.

[63] Ramayah, T., Jason Wai Chow Lee, and Julie Boey Chyaw In. "Network Collaboration and Performance in the Tourism Sector." Service Business 5, no. 4 (October 12, 2011): 411-428. doi:10.1007/s11628-011-0120-z.

[64] Lee, Sang-Gun, Silvana Trimi, and Changsoo Kim. "The Impact of Cultural Differences on Technology Adoption.” Journal of World Business 48, no. 1 (2013): 20-29. doi:10.1016/j.jwb.2012.06.003.

[65] Karika, Anna Elsa. "Facilitating Multi-Stakeholder Engagement for Smart City Development" (2019bm). Haaga-Helia University of Applied Science. 
[66] Werthner, Hannes, Chulmo Koo, Ulrike Gretzel, and Carlos Lamsfus. "Computers in Human Behavior Special Issue on Smart Tourism Systems: Convergence of Information Technologies, Business Models, and Experiences." Computers in Human Behavior 50, (2015): 556-57. doi:10.1016/j.chb.2015.03.042.

[67] Onitsuka, Kenichiro, A. R.Rohman Taufiq Hidayat, and Wanhui Huang. "Challenges for the next Level of Digital Divide in Rural Indonesian Communities.” Electronic Journal of Information Systems in Developing Countries 84, no. 2 (2018): 1-25. doi:10.1002/isd2.12021.

[68] Pilving, T., T. Kull, M. Suškevics, and A. H. Viira. "The Tourism Partnership Life Cycle in Estonia: Striving towards Sustainable Multisectoral Rural Tourism Collaboration." Tourism Management Perspectives 31, (2019): 219-30. doi:10.1016/j.tmp.2019.05.001.

[69] Duedahl, Eva. "Co-Designing Emergent Opportunities for Sustainable Development on the Verges of Inertia, Sustaining Tourism and Re-Imagining Tourism.” Tourism Recreation Research, (2020): 1-16. doi:10.1080/02508281.2020.1814520.

[70] Braun, Patrice. "Regional Tourism Networks: The Nexus between Ict Diffusion and Change in Australia." Information Technology \& Tourism 6, no. 4 (2008): 231-43. doi:10.3727/1098305032781139.

[71] Orchiston, C, and J E S Higham. "Current Issues in Tourism Knowledge Management and Tourism Recovery (de) Marketing: The Christchurch Earthquakes 2010-2011." Current Issues in Tourism 19, no. 1 (2016): 64-84. doi:10.1080/13683500.2014.990424.

[72] Andreopoulou, Zacharoula, Georgios Tsekouropoulos, Christiana Koliouska, and Theodoros Koutroumanidis. "Internet Marketing for Sustainable Development and Rural Tourism.” International Journal of Business Information Systems 16, no. 4 (2014): 446-61. doi:10.1504/IJBIS.2014.063931.

[73] Fernando, Imali N., and Wei Long. "New Conceptual Model on Cluster Competitiveness: A New Paradigm for Tourism?" International Journal of Business and Management 7, no. 9 (2012). doi:10.5539/ijbm.v7n9p75.

[74] El-Said, Osman, and Heba Aziz. "Virtual Tours a Means to an End: An Analysis of Virtual Tours' Role in Tourism Recovery Post COVID-19.” Journal of Travel Research (2021). doi:10.1177/0047287521997567.

[75] Birke, Fanos Mekonnen, and Andrea Knierim. "ICT for Agriculture Extension: Actor Network Theory for Understanding the Establishment of Agricultural Knowledge Centers in South Wollo, Ethiopia.” Information Technology for Development 26, no. 3 (2020): 591-606. doi:10.1080/02681102.2020.1727826.

[76] Bengtsson, Maria, and Marlene Johansson. "Managing Coopetition to Create Opportunities for Small Firms." International Small Business Journal 32, no. 4 (2014): 401-27. doi:10.1177/0266242612461288.

[77] Lama, Sanjay, Sojen Pradhan, and Anup Shrestha. "Exploration and Implication of Factors Affecting e-Tourism Adoption in Developing Countries: a Case of Nepal.” Information Technology \& Tourism 22, no. 1 (January 1, 2020): 5-32. doi:10.1007/s40558-019-00163-0.

[78] Hall, C. Michael, and Allan M. Williams. Tourism and Innovation. Tourism Management. Vol. 30 (2009). Taylor \& Francis. doi:10.1016/j.tourman.2008.11.011.

[79] Gretzel, Ulrike, Matthias Fuchs, Rodolfo Baggio, Wolfram Hoepken, Rob Law, Julia Neidhardt, Juho Pesonen, Markus Zanker, and Zheng Xiang. "E-Tourism beyond COVID-19: A Call for Transformative Research." Information Technology and Tourism 22, no. 2 (2020): 187-203. doi:10.1007/s40558-020-00181-3.

[80] Higgins-Desbiolles, Freya. "Socialising Tourism for Social and Ecological Justice after COVID-19." Tourism Geographies 0, no. 0 (2020): 1-14. doi:10.1080/14616688.2020.1757748.

[81] Lambropoulos, Niki, Panagiotis Kampylis, "Sofia Papadimitriou, Marianna Vivitsou, and Alexander Gkikas. "Hybrid Synergy for Virtual Knowledge Working." Handbook of Research on Electronic Collaboration and Organizational Synergy (2010): 83102. doi:10.4018/978-1-60566-106-3.ch007. 